\title{
Forecasting inaccuracies: A result of unexpected events, optimism bias, technical problems, or strategic misrepresentation?
}

\section{Petter Næss}

Norwegian University of Life Sciences
petter.nass@nmbu.no

Morten Skou Nicolaisen

Aalborg University

mortenn@plan.aau.dk

\author{
Jeppe Andersen
}

Aalborg University

jeppe@plan.aau.dk

\section{Arvid Strand \\ Institute of Transport Economics \\ ast@toi.no}

\begin{abstract}
Based on the results from a questionnaire survey and qualitative interviews among different actors involved in traffic forecasting, this paper discusses what evidence can be found in support of competing explanations of forecasting errors. There are indications that technical problems and manipulation, and to a lesser extent optimism bias, may be part of the explanation of observed systematic biases in forecasting. In addition, unexpected events can render the forecasts erroneous, and many respondents and interviewees consider it to be simply not possible to make precise predictions about the future. The results give rise to some critical reflections about the reliability of project evaluations based on traffic forecasts susceptible to several systematic as well as random sources of error.
\end{abstract}

Article history:

Received: January 1, 2014

Received in revised form: June 30, 2014

Accepted: September 1, 2014

Available online: August 24, 2015

\section{Introduction}

Experience from a number of large-scale investment projects has shown that the traffic forecasts on which decisions to implement the projects were based have often been incorrectly executed and sometimes misleading (see, e.g., Wachs 1989; Flyvbjerg, Bruzelius, and Rothengatter 2003; Flyvbjerg, Holm, and Buhl 2005; Flyvbjerg 2007; Bain 2009; NOU 1998; Nicolaisen 2012). In particular, the study by Flyvbjerg of a large sample of international large-scale transport infrastructure projects has gained wide attention. According to Flyvbjerg (2007) and Flyvbjerg, Holm, and Buhl (2005), misleading quantification of the demand for the chosen solution usually implies that the need for the proposed project is exaggerated. Overly optimistic demand analyses have in particular been documented for railroad projects, especially urban rail.

Inaccurate traffic forecasts have also been found in a study of 179 transport infrastructure projects in the Scandinavian countries (mostly Denmark) and the United Kingdom, including 148 non-tolled

Copyright 2015 Petter Næss, Jeppe Andersen, Morten Skou Nicolaisen \& Arvid Strand

http://dx.doi.org/10.5198/jtlu.2015.719

ISSN: 1938-7849 | Licensed under the Creative Commons Attribution - Noncommercial License 3.0

The Journal of Transport and Land Use is the official journal of the World Society for Transport and Land Use (WSTLUR) and is published and sponsored by the University of Minnesota Center for Transportation Studies. This paper is also published with sponsorship from WSTLUR and the Institutes of Transportation Studies at the University of California, Davis, and the University of California, Berkeley. 
road projects and 31 rail projects (Nicolaisen 2012). In line with the results from the studies by Flyvbjerg, Holm, and Buhl, as well as a number of other studies (NAO 1988; Pickrell 1990; Fouracre, Allport, and Thomson 1990; Parthasarathi and Levinson 2010; Welde and Odeck, 2011), Nicolaisen (2012) found a tendency of underestimated traffic for road projects (11 percent on average) and overestimated passenger forecasts for rail projects ( 20 percent on average). There are also examples of underestimation of the demand in situations where growth is not considered desirable. This has occurred in connection with proposed road investments in urban areas where non-growth of car traffic is a goal (Næss, Flyvbjerg, and Buhl 2006). Misleading analyses of what will happen if a proposed investment project is not implemented have in some cases left the impression that the proposed solution is necessary in order not to end in a future situation few would wish (Næss 2011). Nicolaisen (2012) found a tendency of overestimated forecasts for the traffic volumes (and hence also the level of congestion) on the existing road network in the absence of road building (7 percent on average), thus supporting previous case studies where "pessimism bias" against the "zero alternative" have been found.

While there appears to be considerable consensus within the literature on the findings that traffic forecasts are inaccurate, there is less agreement on the causes of observed forecasting inaccuracies. Mackie and Preston (1998) listed 21 potential sources of error and bias in transport project evaluation, pertaining to objectives, definitions, data, models, and evaluation conventions. According to Flyvbjerg (2007), various sources of forecasting errors for transportation infrastructure projects can be boiled down to three main categories: technical, psychological, and political-economic explanations. In Flyvbjerg's view, shortcomings in the forecasting techniques, inadequate data, "honest mistake," and the inherent uncertainty in predicting the future, etc. all belong to the category of technical explanations. His term "psychological explanations" refers to a widespread human tendency of wishful thinking, causing project promoters and planners to underestimate problems and exaggerate benefits of proposed projects. Typically, such "optimism bias" results in underestimated construction costs and environmental impacts and exaggerated benefits in terms of congestion relief or new public transport passengers. Flyvbjerg's last category, the political-economic explanations, refers to situations where project promoters and planners are deliberately and strategically overestimating benefits and underestimating costs in their forecasts to increase the likelihood that the projects will be approved and funded (Flyvbjerg 2007, pp. 583-584).

The explanations given in the research literature of inaccuracy and bias in traffic forecasting have been criticized for drawing inferences mainly from observed deviations between forecasted and actual traffic (e.g., Osland and Strand 2008; Nicolaisen 2012; Andersen 2013; Eliasson and Fosgerau 2013). The studies made by Flyvbjerg and COWI (2004) and Flyvbjerg (2007) do, however, also include interviews with a number of public officials, planners, and consultants who had been involved in the development of transportation infrastructure projects, and the same applies to the older study by Wachs (1989). There is, however, lack of evidence in these studies about the representativeness of the statements given by those interviewed. Moreover, the different kinds of explanations are dealt with in the above-mentioned studies as if they were mutually exclusive, although theoretical considerations and case studies of transport-planning processes indicate that they can be highly entangled and should be seen as complementary rather than competing (Næss 2011; Andersen 2013). Finally, we think the "technical explanations" category discussed by Flyvbjerg (2007) is too broad and heterogeneous to make up one single category. In our view, "inherent problems in predicting the future," which are included in Flyvbjerg's conceptualizing of technical explanations (see above) is not a technical shortcoming but an ontological precondition and should be classified as such (Næss and Strand, 2012).

Based on empirical data from the Scandinavian countries, this paper discusses what evidence can be found in support of different explanations of forecasting errors: ontological explanations (unexpected events), optimism bias, technical problems, and strategic misrepresentation. The structure of the paper 
is as follows: In the next section (2), the research design, methods, and data material of the study will be outlined. Section 3 presents the key findings about the relevance attributed by our respondents and interviewees to different explanations of forecasting inaccuracy, addressing first ontological explanations, then optimism bias, thereupon technical explanations, and finally strategic misrepresentation. A brief discussion and some concluding remarks are given in the last section (4).

\section{Research design and methods}

The study was carried out as part of a larger research project, Uncertainties in Transport Project Evaluation (UNITE), which was conducted jointly by the Danish Technical University, Aalborg University, and a number of sub-contractors. The part of the project on which this paper is based included in-depth research interviews, a questionnaire survey, and document studies.

Sixteen key stakeholders in the production or use of traffic forecasts as decision support were interviewed: model developers, consultants, traffic planners, transport-sector civil servants involved in policy making at the national or local level, and politicians with transportation policy as a field of responsibility. The interviewees were selected in order to gain information from persons having roles in the forecasting process. All the interviewees were from Danish institutions, except two Swedish researchers involved in the development of what was characterized by other interviewees as state-of-the-art transport models. The Danish focus was mainly due to practical considerations, because all interviews were carried out by researchers located at Aalborg University. The interviews took place from 2010 to 2012, lasted from one to three hours, and were tape-recorded and subsequently transcribed. The discussions were semistructured and open-ended, following a rough interview guide but with considerable scope for adjusting the topic to issues with which the interviewee was particularly preoccupied. The interviews were not confined to particular projects but drew on the interviewees' general knowledge on topics related to modeling. A qualitative content analysis of the interview transcripts was conducted, following an interpretation scheme tailor-made for the study. This scheme comprised a number of detailed research questions that we, as researchers, tried to answer, based on the information given by the interviewees (first interpreting the statements in each separate interview and then synthesizing across the 16 interviews). In this paper, we have primarily drawn upon the interviews with persons actively involved in transport model construction or the production of traffic forecasts, although we have also to some extent (in the concluding section) made use of material from interviews with politicians.

The questionnaire survey was conducted in 2010 among the same categories of stakeholders. Many of the questions on the questionnaire were formulated as statements with which the respondents were asked to indicate their extent of agreement along a five-point Likert scale. Compared to the interviews, the questionnaires covered a broader Scandinavian context. Invitations to respond to web-based questionnaires were distributed by e-mail to transport-related university research units, transport units in consultancy firms, road and rail directorates, transport sections in regions/municipalities, transport/ environment-related non-governmental organizations (NGOs), and parliamentary transport committees in Denmark, Norway, and Sweden. The mail recipient at the contact address was asked to forward the invitation to those employees or elected officials for whom the questionnaire would be relevant. National-language versions of the questionnaire were provided for each country. After one reminder mailing, 453 completed questionnaires were obtained. Roughly 40 percent of the respondents were from Denmark, another 40 percent were from Norway, and the remaining 20 percent were from Sweden. In this paper, the statistics are based mainly on the sub-sample of 92 Scandinavian experts most closely involved in model-based traffic forecasting, constructing transport models, or producing traffic forecasts. The reason for concentrating on this sub-sample is that we consider this group of respondents to be particularly qualified for providing an "insider view" on potential causes of forecasting inaccuracy. 
In addition to interviews and questionnaires, the paper also draws on documents where information has been found about forecasting inaccuracy for Danish, other Scandinavian, and British road projects and the extent to which Danish traffic forecasters and transport modelers have been aware of the phenomenon of induced traffic. Each of these two main categories of information were first systematized and analyzed in two Ph.D. theses (Nicolaisen 2012; Andersen 2013).

\section{$3 \quad$ Findings}

In this section, the key findings of the study will be structured according to the following four main categories of explanations for forecasting inaccuracies: ontological explanations, optimism bias, technical explanations, and strategic misrepresentation. Under each category, findings from the qualitative interviews as well as from the questionnaire survey will thus be presented.

When interpreting the results from the questionnaire survey, it should be noted that some of the questions were asking specifically for the respondents' opinions on the roles of various circumstances as explanations of forecasting inaccuracies, whereas other questions simply asked for the respondents' opinions about the occurrence of the circumstances mentioned. From theoretical considerations, the latter circumstances could also be expected to contribute to forecasting inaccuracy, but this was not specifically mentioned in these questions. Information on the question category to which each statement belongs is given in footnotes to the figures. Since the circumstances asked about in the questions not including any reference to forecasting error may exist also in situations where they do not cause such errors, there is a risk of exaggerating the perceived role of these circumstances as reasons for forecasting inaccuracies, compared to the characteristics mentioned in the questions explicitly referring to forecasting inaccuracy. This should be borne in mind when interpreting the results.

Moreover, for the questions asking about potential causes of forecasting inaccuracy, there are relatively high proportions of missing answers (20-22 percent). This might reflect that some respondents, although perhaps having an opinion about the occurrence of the phenomena asked about, do not have any concrete experience or awareness of the ways in which they may lead to forecasting errors, and they might therefore feel unable to answer these questions. For example, some respondents know very well their specific role in the forecasting process, but are not called upon to compare their estimates with reality once projects go ahead and will therefore not be in a position to truly evaluate the impact of different types of inaccuracies. In such cases, missing answers might be interpreted as similar to "don't know." But missing answers could arguably also be interpreted as an indication of non-interest in the issue asked about, where the absence of any positive attribution of any role of the circumstance mentioned as a contribution to forecasting error might signify that the respondent does not consider the circumstance as a main source of forecasting error ${ }^{1}$. It is hard to say which one of these ways of interpreting missing answers is the most reasonable one ${ }^{2}$. For the questions where the rates of missing answers were high, we have therefore chosen to display the percentages for each answer alternative calculated from the number of valid answers as well as from the total number of respondents of the sub-sample included in the study.

\subsection{Ontological explanations}

Six of the questions in the questionnaire concerned different ways in which unexpected future events can jeopardize forecasts. Many of the factors influencing traffic development depend on inherently unpredictable geopolitical trajectories as well as contested political decision-making. Since the difficulty in predicting future traffic volumes is largely due to the relative openness of the socio-spatial systems within which transport projects are implemented (Bhaskar 2008; Danermark et al. 2001), we consider the impossibility of making precise traffic forecasts as an ontological condition (Næss and Strand 2012). 
In line with this, explanations referring to unpredictable and unforeseen future events as a source of forecasting errors will be referred to as ontological explanations. Our category of ontological explanations includes several explanations referred to by Flyvbjerg (2007) and Flyvbjerg, Holm, and Buhl (2002, $2005)$ as technical explanations. Since the difficulty in predicting these unexpected events is an ontological condition rather than a technical shortcoming of the forecasting tools, we think the term "ontological explanations" is more appropriate than the term "technical explanations."

Figure 1 shows the respondents' degree of agreement or disagreement with different ontological explanations of forecasting errors. Among the total sub-sample, 53 percent positively express whole or partial agreement that the impossibility of making precise predictions about the future is a main source of forecasting inaccuracy, whereas only 22 percent express full or partial disagreement. If only valid answers are considered, the proportion agreeing in the statement is 68 percent.

The general impossibility of knowing beforehand how all relevant factors of influence will develop in the future is also reflected in explanation (b) in Figure 1, where different development of critical input data from what was assumed in the forecast is pointed at as a main source of forecasting error. Forty-five percent of the total sub-sample positively supports this explanation fully or partially, whereas the percentage disagreeing is only 10 percent. Among those who have given valid answers, 57 percent expresses full or partial agreement.

The widespread disbelief in the possibility of making exact predictions about the future is reflected in the following statement by one of the interviewees:

No damned person knows whether things really will turn out [as expected] some 10 years ahead...Indeed, [for the forecast to be accurate,] the development has to go in the same direction. But there are, of course, a lot of things that may change, both in the project specifications and in the overall conditions. (Civil servant in the Ministry of Transport, Denmark, in interview July 2011)

Whereas the above explanations (a) and (b) in Figure 1 refer to general difficulty in predicting future events and situations, the four remaining explanations refer to specific types of unexpected events frequently mentioned as sources of forecasting errors. Since these specific circumstances include only a few of the many unexpected kinds of events that may jeopardize forecasting accuracy, it is hardly a surprise that the percentages considering them as main sources of erroneous forecasts are lower than for the explanations referring to general uncertainty about the future. The percentages of the total subsample considering design changes during construction, unforeseen land use changes, or unforeseen development of other transport infrastructure as main sources of forecasting inaccuracy vary between 34 percent and 27 percent (43 percent and 34 percent when considering only valid answers), whereas the percentage attributing inaccurate forecasts to delays during construction is a bit lower (23 percent among the total sub-sample and 29 percent among valid answers). It should be noted that the proportions disagreeing in the explanation statements are also lower for the more specific explanations than for the statements referring to general difficulty in predicting the future. Even for the explanations obtaining the lowest proportions of "agree" and "partly agree," the proportions fully or partly agreeing are more than twice as high as the proportions fully or partly disagreeing. This reflects much higher percentages of "neutral" and "don't know" for the more specific explanations. Whereas only 3.3 percent of the total sub-sample has ticked for these answers regarding general impossibility of precise predictions about the future, the proportions make up 47 percent for the "delays in construction" explanation. This probably reflects that many respondents do not have any specific experience with these circumstances as sources of forecasting errors, while most of them probably have experienced the general difficulty in predicting 


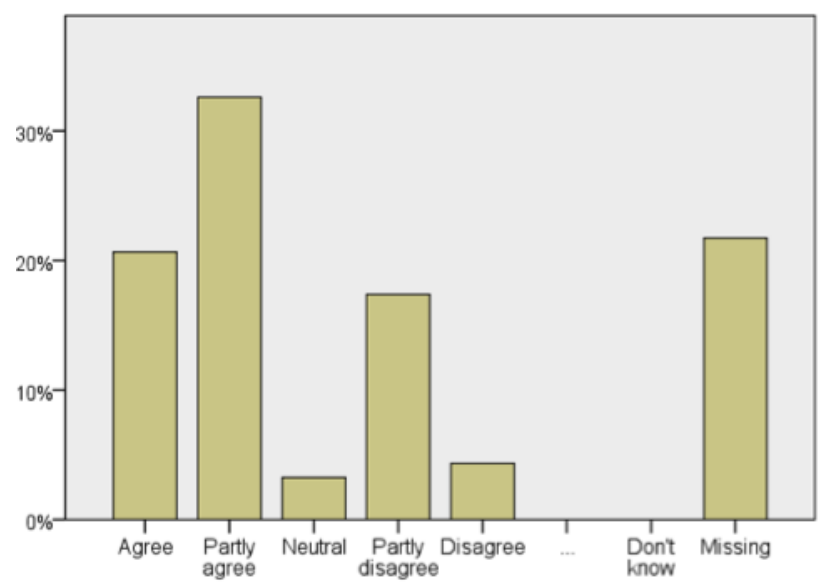

a) It is simply not possible to make precise predictions about the future

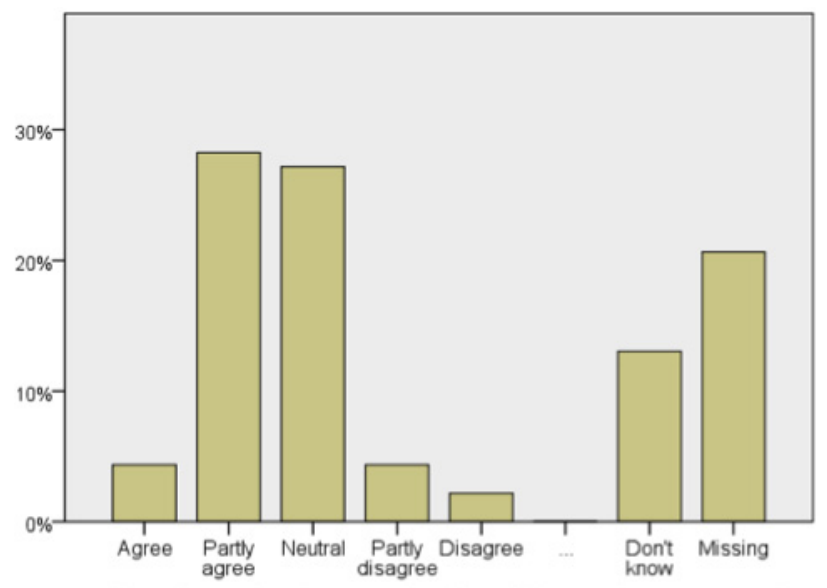

c) Land use development is often different than expected the future-in traffic forecasting as well as in life in $g$

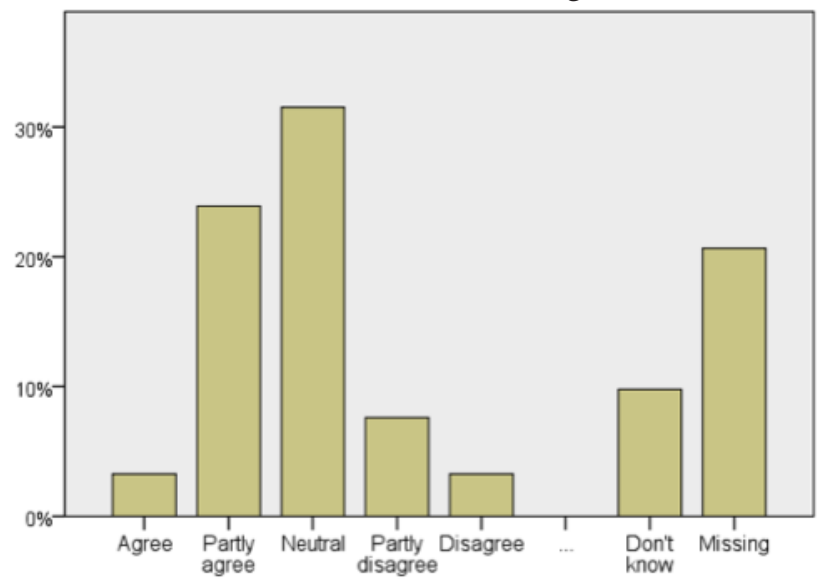

e) Other transport infrastructure in the same corridor does not develop as expected

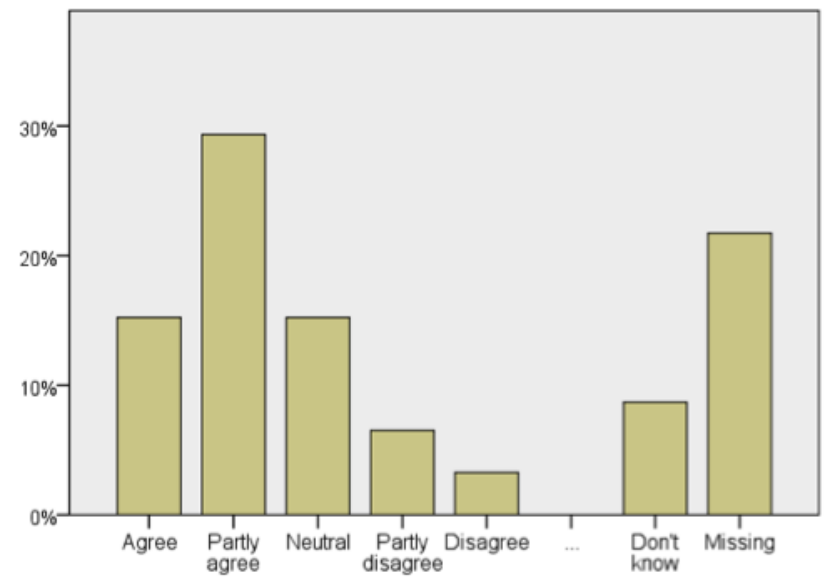

b) The development of critical input data is different than what is assumed in the forecast

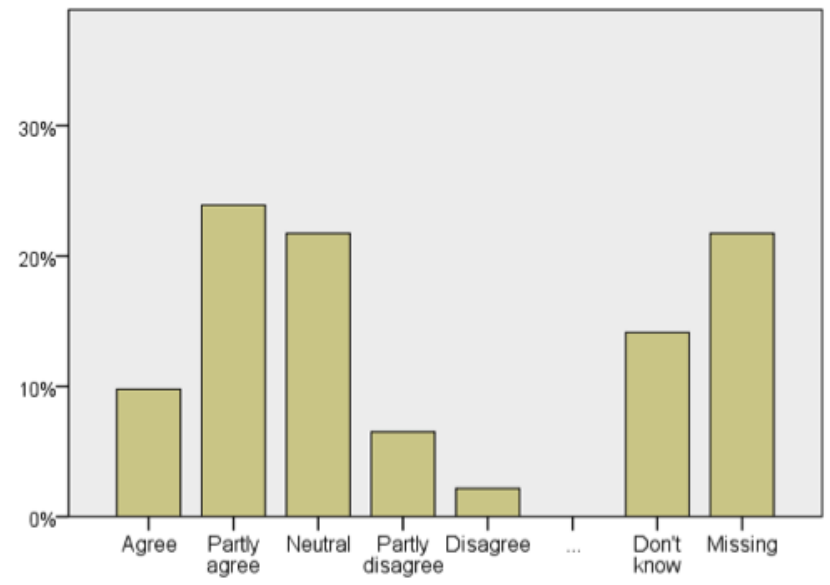

d) Design changes during construction lead to different projects than those that the forecast are based on

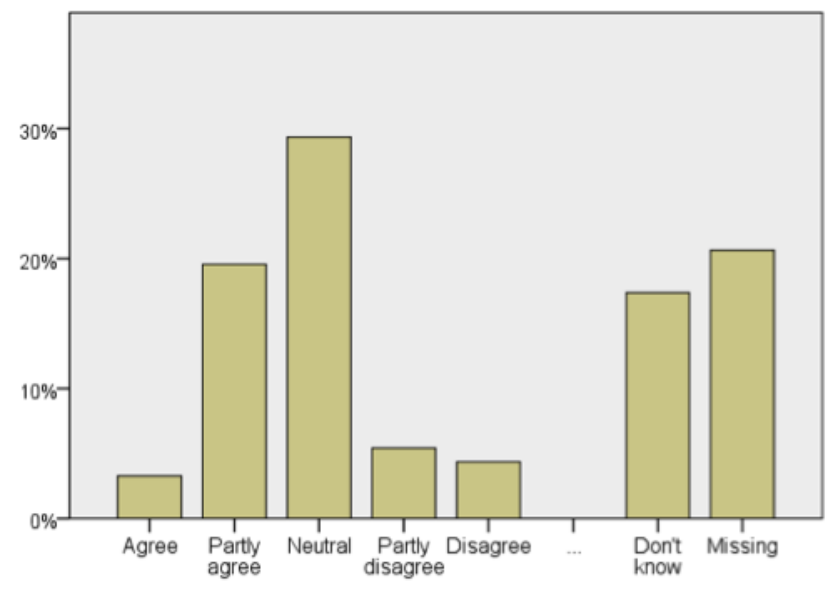

f) Delays during construction lead to different conditions than what is forecasted for

Figure 1: Respondents' opinions about different explanations associated with unexpected events as a main source of forecasting inaccuracy ${ }^{3}$.

Note: Percentages of the total sub-sample. $\mathrm{N}=92$ Scandinavian experts involved in model-based traffic forecasting as construc- 
tors of transport models or producers of traffic forecasts.

\subsection{Optimism bias}

The explanation category referred to as optimism bias, understood as a psychological tendency of wishful thinking, was not explicitly addressed in the questionnaire. Nor does our interview material suggest that such a psychological mechanism is a very important cause of error in traffic forecasting. Also when asking the questionnaire respondents about optimism bias more generally, without mentioning explicitly the psychological tendency of wishful thinking (Figure 2), the percentages fully or partly agreeing that this is a main source of forecasting inaccuracy are relatively modest (22 percent among the total subsample and 26 percent among valid answers). Although the proportions of "neutral" and "don't know" are quite high, the proportions of respondents fully or partially disagreeing that forecasts turn out to be inaccurate because they are overly optimistic about the success of the project are higher than the proportions fully or partly agreeing with this statement.

Slightly higher proportions than in the above-mentioned reference to general over-optimism as an explanation agree with the more specific statement that traffic forecasts are biased because they are too optimistic due to clients specifying unrealistic assumptions about future conditions. Here, the optimism bias is attributed to the clients and not to the forecasters themselves. This might, on the one hand, reflect uneasiness among the forecasters to admit that they are themselves overly optimistic, making them instead blame the clients. But we consider it more likely that the statement reflects that several forecasters have actually experienced that clients have persuaded them into feeding the forecasting models with input data resulting in more optimistic forecasts than the forecasters themselves consider realistic. The question then remains whether this reflects wishful thinking among the clients or is an example of strategic misrepresentation. There is a the fine line between the categories of "strategic misrepresentation" and "optimism bias," as many of those working on forecasting projects have something to gain from producing "desirable" outcomes. We will return to this issue below.
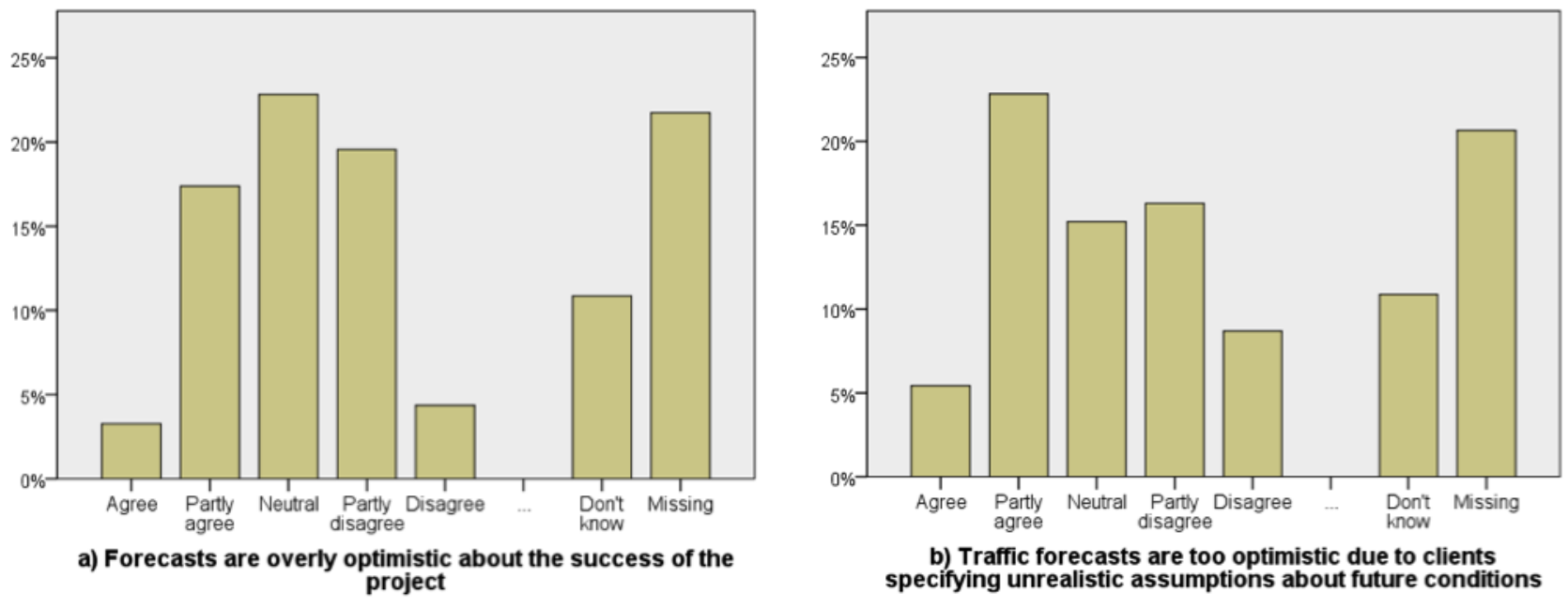

Figure 2: Respondents' opinions about different explanations associated with optimism bias as a main source of forecasting inaccuracy.

Note: Percentages of the total sub-sample. $\mathrm{N}=92$ Scandinavian experts involved in model-based traffic forecasting as constructors of transport models or producers of traffic forecasts. 


\subsection{Technical explanations}

While we maintain that the occurrence of unexpected events rendering the assumptions of the forecasting models obsolete and erroneous is a cause of forecasting inaccuracy belonging to the ontological and not the technical category of explanations, technical explanations do exist as well. Some of the shortcomings of existing transport models can probably be reduced or eliminated through future research and development, but until such improved models have been developed there will be some forecasting inaccuracy due to these potentially solvable model problems. Moreover, the models used in practical forecasting are for several reasons not always the best ones. There may also be difficulties in obtaining good input data necessary for model calibration.

The two upper graphs of Figure 3 refer to the imperfectness of existing traffic models and the use of models of less than state-of-the-art quality. A quite high proportion of the respondents (63 percent) fully or partially agrees that more advanced models would yield more accurate results, and the proportion holding that resource constraints result in traffic forecasts often being based on relatively simple models are also rather high (52 percent). For the above explanations, the proportions fully or partially agreeing are two and a half to three times higher than the proportions fully or partially disagreeing. Although the two above-mentioned questions were not introduced by any text explicitly coupling model imperfectness with forecasting inaccuracy, we find it plausible to interpret respondent statements about needs for model improvement and frequent use of less-than-optimal models as indirect indications of model shortcomings as sources of forecasting inaccuracies. ${ }^{4}$

The use of a model not belonging to the most advanced ones in transport planning practice was commented on as follows by one of our interviewees:

You may well use a traffic model that is not as top-tuned as it ought to be. But since the same model is used to analyze all four [road-building alternatives], some of its errors will be eliminated when comparing across. (Model developer/consultant, Denmark, in interview June 2010)

We also asked the respondents to state how well-abled they considered traffic models to be for performing certain tasks frequently mentioned in the literature as model weaknesses: to reflect impacts of land-use changes, to reflect impacts of changes in the public transport system, and to forecast the traffic-increasing effect of transport infrastructure improvement (induced traffic). High proportions of disagreement in the suitability of traffic models for performing these tasks would then serve as indications that these specific model shortcomings were partial explanations for forecasting inaccuracies.

The results show that the majority of respondents (68-70 percent) consider traffic models to be good at reflecting impacts of land-use changes and impacts from changes in the public transport system. In contrast, only around 17 and 21 percent, respectively, disagree fully or partially in the performance statements about these aspects.

The respondents' faith in the models' predictive ability is, however, substantially lower when it comes to the traffic-increasing effect of transport infrastructure improvement. Among the total subsample, 39 percent fully or partially agrees that forecasts tend to become inaccurate because traffic models are poor at forecasting the effects of induced traffic, compared to 24 percent who fully or partially disagree. If only the valid answers are included, 49 percent fully or partially agrees while 30 percent fully or partially disagrees. 


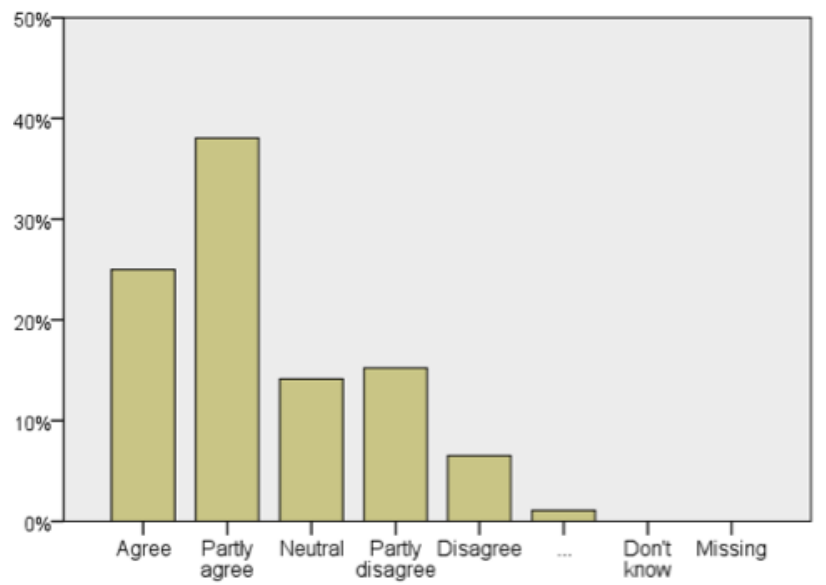

a) More advanced models would yield more accurate results

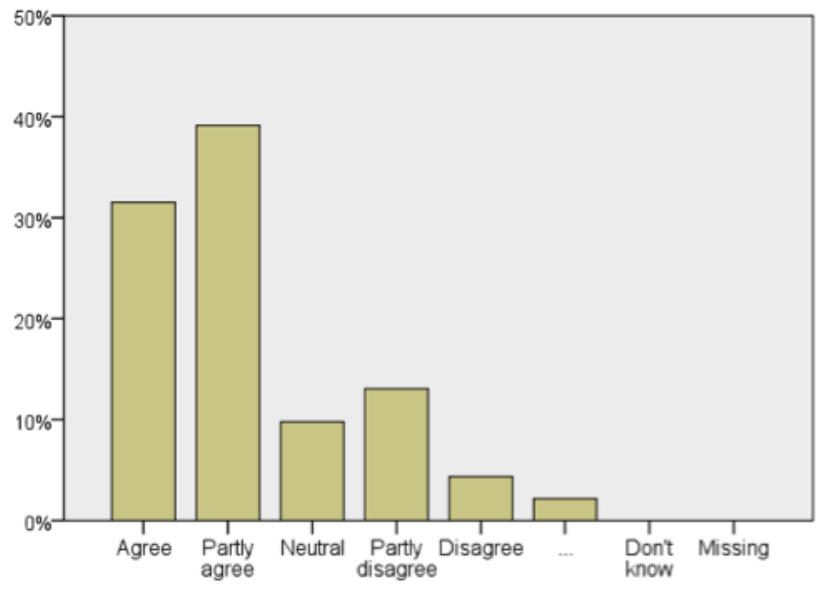

c) Traffic models are good at reflecting the impact on traffic resulting from changes in land use

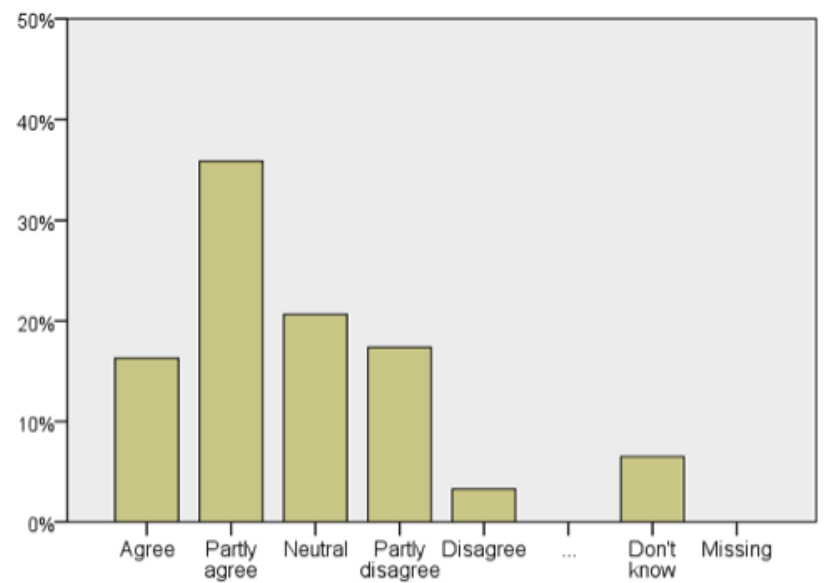

b) Resource constraints result in traffic forecasts often being based on relatively simple models

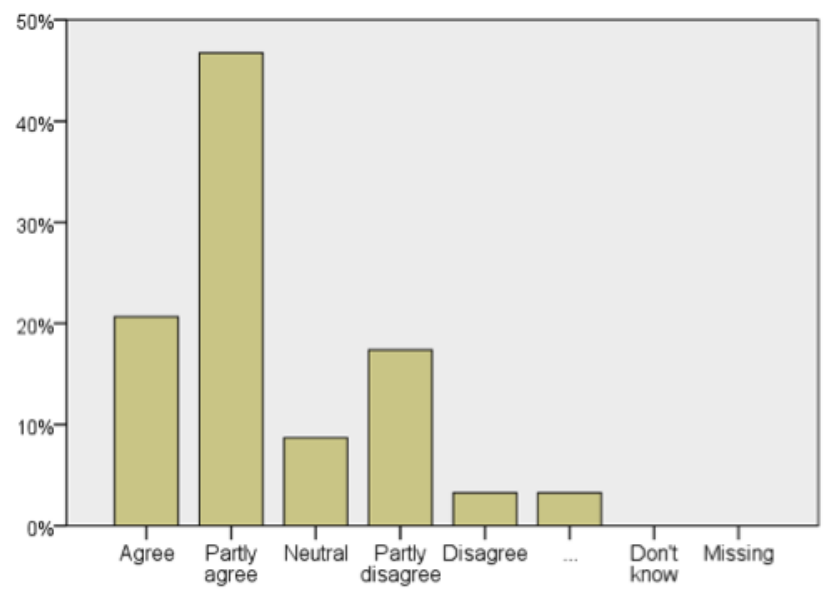

d) Traffic models are good at reflecting the impact on traffic resulting from changes in public transport systems

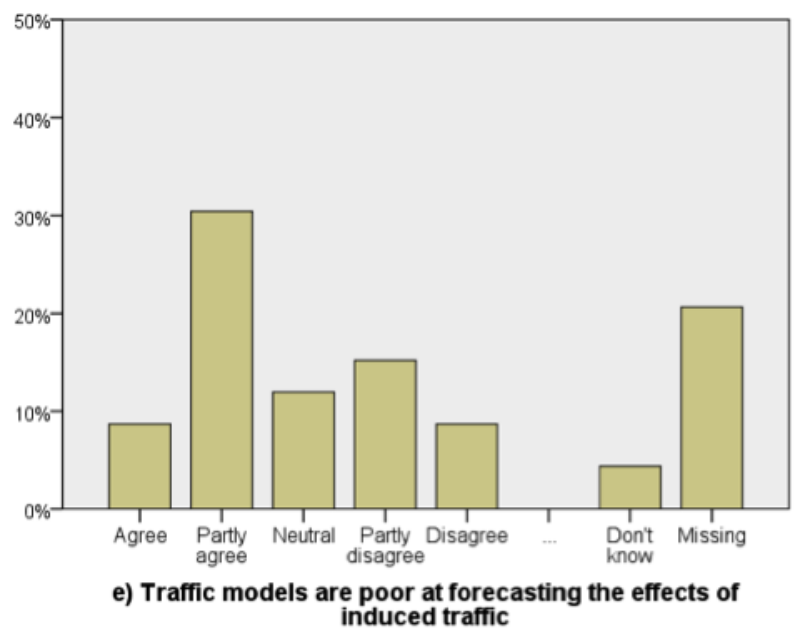

Figure 3: Respondents' opinions about different explanations associated with technical shortcomings as a main source of forecasting inaccuracy ${ }^{5}$.

Note: Percentages of the total sub-sample. $\mathrm{N}=92$ Scandinavian experts involved in model-based traffic forecasting as constructors of transport models or producers of traffic forecasts. 
An issue here, of course, is whether the respondents are sufficiently knowledgeable about the nature and magnitude of traffic impacts from land-use changes, changes in the public transport system and road capacity increases in different contexts to discover model shortcomings related to these aspects. The questionnaire included questions asking respondents to express their agreement or disagreement with statements about the existence of such impacts. For each of the three above-mentioned kinds of impacts, around three out of four respondents fully or partially agreed that such changes have significant influences on travel behavior (and for road capacity expansion that the effect is an overall increase in traffic), whereas only 6-16 percent were fully or partially disagreeing. These figures still do not necessarily entail that the respondents consider that traffic models tend to underestimate the size of such changes - the perceived error could also be that the effects were exaggerated. Regarding the impact of road capacity increase, some of the modelers and forecasters who participated in the qualitative interviewees and who recognized induced traffic as a real phenomenon, considered it to be of modest magnitude and a much more limited phenomenon geographically and topically than depicted in the academic literature (Nrss et al. 2014).

In the quote above, the use of a model with recognized shortcomings was defended by one of our interviewees. This model did not take induced traffic into consideration, but since the resulting error would be nearly the same for all the road-building alternatives, the model was considered to be good enough for its purpose. Ignoring induced traffic will, however, lead to biased results when comparing road construction with the no-build-alternative. Neglect of induced traffic tends to systematically underestimate adverse traffic-related environmental effects, and in congested regions it is also likely to severely exaggerate time-saving benefits from road construction (Jonsson and Johansson 2006; Næss, Nicolaisen, and Strand 2012). Omission of induced traffic can thus serve to place proposed road-building projects in a more flattering light than what would be the case if the traffic-increasing effect of road construction were taken into account. The question therefore arises: Is the continuing use of models ignoring or grossly underestimating induced traffic, despite strong criticism leveled by academics as well as stakeholders in local planning processes against this practice ${ }^{6}$, a merely technical issue?

\subsection{Strategic misrepresentation}

One of the questions in the questionnaire survey asked explicitly about deliberate manipulation as a possible source of forecasting error. Not many respondents agree in this being a main source of forecasting inaccuracy. As can be seen in Figure 4, only 14 percent of the total sub-sample express full or partial agreement, while 42 percent fully or partially disagree. Counting valid answers only, the percentages are 18 percent and 54 percent, respectively. A widespread normative rejection of deliberate manipulation is also reflected in the qualitative interviews, as illustrated in the following quote:

We must be able to solve the tasks for both sides in a dispute. We need to be able to say "This is precisely the way we do it." (consultant, Denmark, in interview July 2010)

It is well known from the literature on questionnaire survey methods that socially undesirable and unacceptable behavior generally tends to be underreported (e.g., Bradburn, Sudman and Wansink 2004). Our sub-sample consists of respondents who are themselves deeply involved in model construction and the production of traffic forecasts. Admitting that forecasting inaccuracies might stem from deliberate manipulation might place their own profession in an unflattering light. Viewed this way, one might perhaps have expected the proportions fully or partially agreeing in the statement to be even lower. The fact that 14 percent of the total sample (i.e., 13 respondents) identifies deliberate manipulation as a main source of forecasting inaccuracy is in this perspective not very reassuring. Moreover, when 


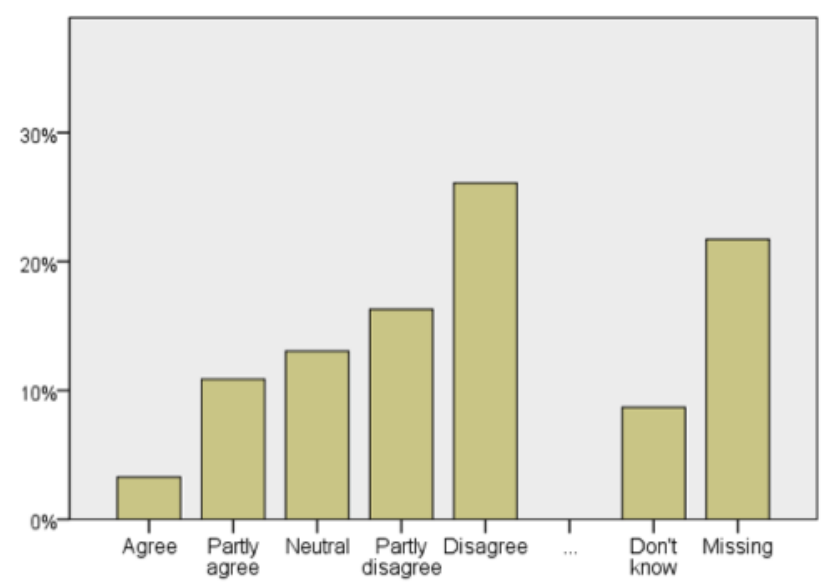

a) Forecasts are deliberately manipulated by the proponents of a project

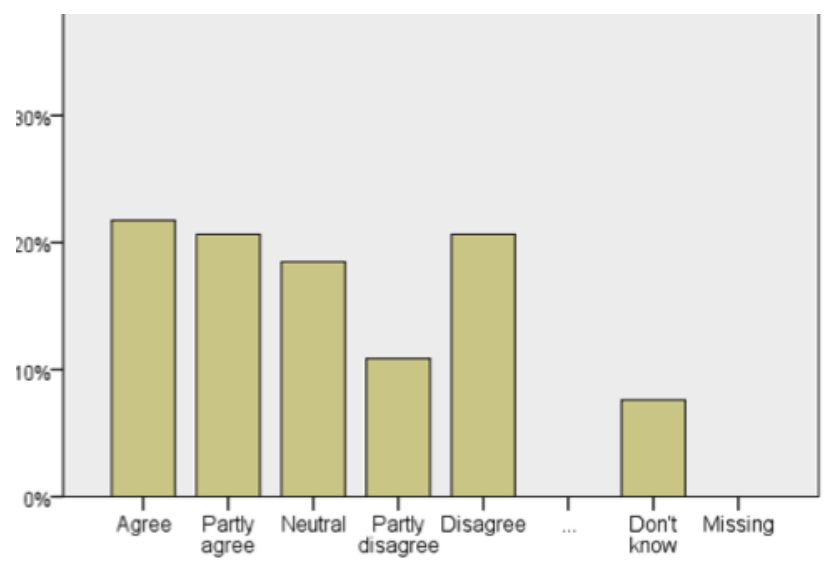

c) Forecasters are under pressure to produce forecasts that agree with their clients' or superiors' visions

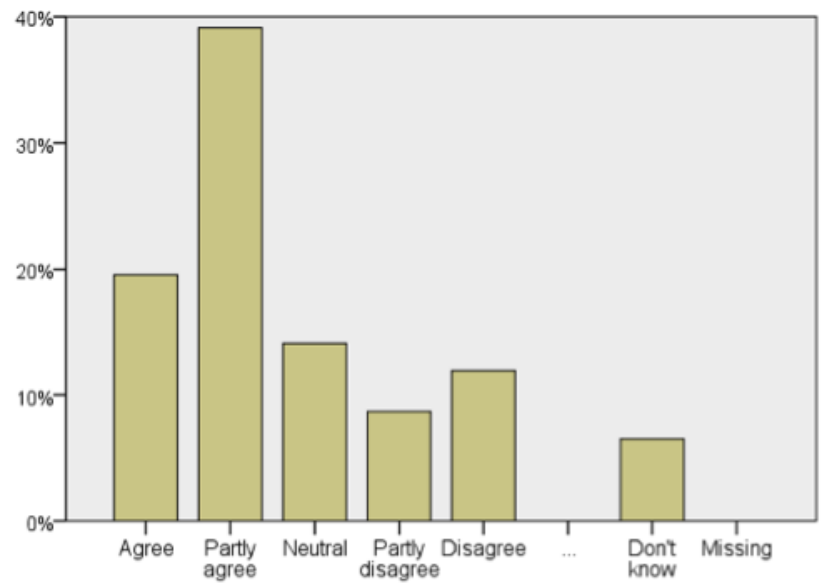

b) Traffic forecasts are often used to justify projects for which a political decision to build have already been taken

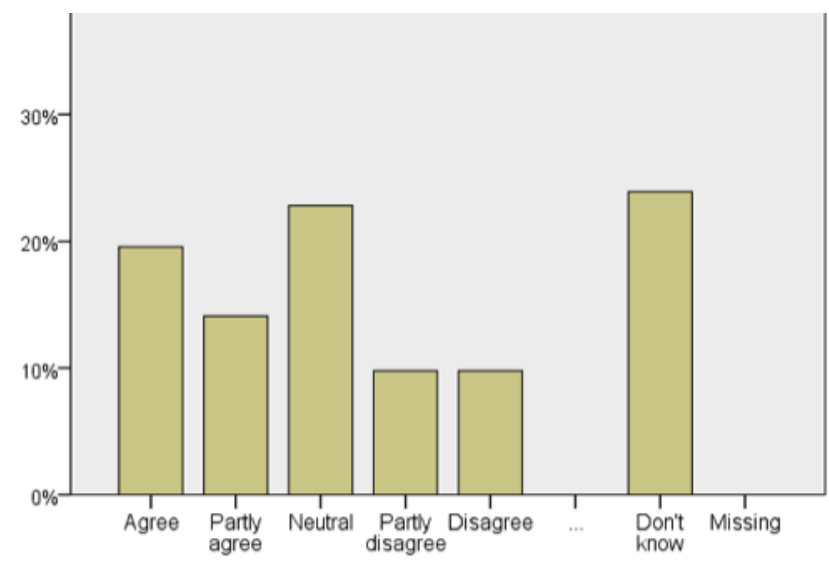

d) Due to systematic underestimation of rail benefits in CBAs, proponents have to provide optimistic forecasts

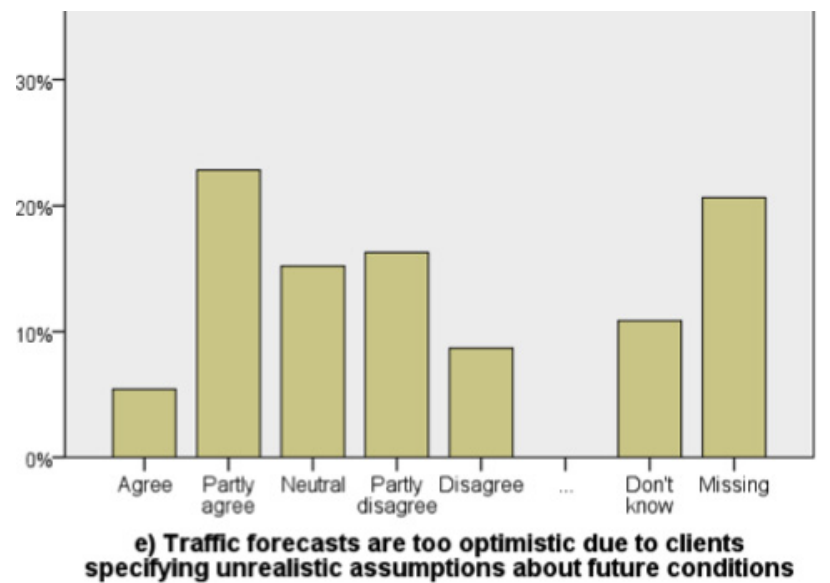

Figure 4: Respondents' opinions about different explanations associated with strategic misrepresentation as a main source of forecasting inaccuracy ${ }^{7}$.

Note: Percentages of the total sub-sample. $\mathrm{N}=92$ Scandinavian experts involved in model-based traffic forecasting as constructors of transport models or producers of traffic forecasts 
asking about specific practices that might be part of, or related to, strategic misrepresentation, higher proportions of respondents give affirmative answers.

We have already (in the section on optimism bias) mentioned that 28 percent of the total subsample (and 36 percent among those who have given valid answers) considers forecasters' acceptance of unrealistic assumptions imposed by their clients about future conditions to be a main source of erroneous forecasts. The following quote suggests that dialectic interplay is sometimes taking place between political preferences about future development and the decision-support material delivered by forecasters:

Interviewee: Is the acceptance of the [very high] passenger forecasts for the xxx rail line a result of naïve optimism or deliberate manipulation, given the available information?"

Parliamentary politician: "I would rather say: It is at least an attempt to avoid running into a difficult situation. And maybe also a belief that there are no limits... Obviously, if you expect economic growth of 2-3 percent annually over the next 40 years, there will be a lot of demand for all kinds of things. Then there is the question of whether this rise in consumption is consistent with the adopted environmental goals. Which it isn't. But the non-achievement of these goals will not be apparent until later. So, although the importance of this explanation is difficult for me to gauge, what may be the case is that decision-makers want to avoid putting themselves in a situation where they have to choose. I think some politicians are very much aware that they should not make too much queries into this [the assumptions underlying the forecasts], because then they would have to make a choice." (Member of the Danish Parliament, in interview January 2011)

The respondents' answers to the questions about their agreement/disagreements with statements b, c, and d in Figure 4 also give reasons for concern. Forty-eight percent of the respondents fully or partially agrees that traffic forecasts are often used to justify projects for which a political decision to build has already been taken, whereas only two thirds of this percentage (32 percent) disagrees. This is also pointed at in some of the qualitative interviews, as illustrated by the following quotes:

Very often... what the politicians do is to choose the forecast leading to the decision they [beforehand] prefer... If you change the assumptions just a little bit, the resulting changes will simply overrule its [the model's] finesses." (Model developer/Consultant, Denmark, in interview June 2010.)

The point is anyway that it ends up in horse trading. Then you try to construct some rational arguments for what you do." (Member of the Danish Parliament, in interview January 2011.)

Respondents fully or partially agreeing that forecasters are under pressure to produce forecasts that agree with their clients' or superiors' visions (41 percent) outnumber those who fully or partially disagree with this statement (32 percent). The following quote illustrates some of the dynamics that can make forecasters yield to such pressure:

I refuse to believe that those carrying out this work [modeling] are not influenced by knowing that the result they arrive at is to be used by agencies that are subsequently supposed to order new studies." (Member of the Danish Parliament, in interview January 2011) 
Perhaps even more worrisome are the respondents' opinions about a statement saying that proponents of rail projects have to provide optimistic forecasts to get projects approved, since rail benefits are systematically underestimated in cost-benefit analyses. Thirty-four percent agrees fully or partially with this statement, while only 20 percent expresses full or partial disagreement. As illustrated by the following quote, forecasters may also be influenced by attitude-based preference for certain modes of transport:

People working in the rail sector are usually quite interested in railroad and they really like trains - in a way that — sometimes you don't feel that they are really neutral to their study object. That's at least my impression. And that impression is based on-mainly from my work at xxxx, where people working in the rail sector they kind of like rail... We have had some projects in Sweden, where the assumptions were, I would say, a little bit rough—or optimistic — where things weren't exactly_-I don't think it was done the correct way...It's...quite well known in Sweden that the Nordre Botnia Banan railroad along the north—-the east coast north of Gävle up to...Sundsvall and Umeå-there the forecast wasn't really based—wasn't made on the correct assumptions I think. And...I'm not the only one who questions this forecast. (Swedish consultant and researcher, in interview October 2011)

It should be noted that the proportions of "neutral" and "don't know" answers are particularly high for the last question in Figure 4 (46 percent) and considerable also for the statements about a priori decisions and pressure from clients (around 25 percent). Nevertheless, the pattern emanating from the answers in Figure 4 and the above quotes from the qualitative interviews clearly indicates that strategic misrepresentation should not be dismissed as an important source of forecasting error.

\section{$4 \quad$ Concluding remarks}

Our material suggests that several categories of explanations exist for traffic forecasting inaccuracy in a Nordic context. Instead of regarding ontological, psychological, technological, and political/institutional explanations as competing categories, we consider it more fruitful —and better in line with our data - to see these different explanatory categories as complementing each other. In particular, our respondents and interviewees are of the opinion that ontological, technological, and political/institutional circumstances are important sources of forecasting errors, whereas the support of psychological explanations is less clear in the material.

Ontological conditions - the inevitability of unexpected events in open systems-are recognized by the respondents and interviewees as important causes of forecasting errors. Such unexpected events result in large, non-systematic differences between forecast and actual traffic. The large standard deviations of the inaccuracy levels found in studies comparing actual and forecast traffic volumes are mainly attributable to this category of explanations.

The human psychological tendency of judging outcomes of planned actions too optimistically is identified as a source of error by a relatively moderate number of respondents and by few interviewees. In contrast, poor technical model quality is widely held by our respondents and interviewees as a source of inaccuracy. The inaccuracies in question are in the form of unsystematic deviations as well as systematic bias - the latter occurring, for example, when using transport models that do not take induced traffic into consideration. There is, however, reason for critically asking whether continued use of technically biased models should be understood as an "innocent" and purely technical matter. As argued by Næss (2011), the reasons for sticking to transport models that exaggerate time savings and underestimate negative environmental impacts of road building may well be of a political/institutional nature (see also Andersen 2013). If someone actually wanted to manipulate forecasts in order to place a project or a 
policy in a flattering light, choosing model assumptions that make the project outcomes look favorable is arguably the way such manipulation could be done with the least risk of being discovered.

Most respondents and interviewees disagree, however, in the explicit and general statement that forecasting errors may be due to deliberate manipulation. But many respondents (and some interviewees) consider various specific kinds of misrepresentation (justification of already chosen projects, satisfying clients' opinions, or "compensating" for bias in cost-benefit analyses of rail projects) as quite widespread. Since these kinds of practices are likely to lead to skewed forecasts, they can reasonably be identified as sources of forecasting bias. So while we do not claim that strategic misrepresentation is the only or dominating source of forecasting error, we do find evidence indicating that political/economic causes of biased forecasts cannot be ruled out. The limited size of our sample of respondents should still be borne in mind.

Incentives for strategic misrepresentation clearly exist. Among our sub-sample of 145 Scandinavian politicians at both the national and local level, large majorities ( 82 and 73 percent, respectively) consider traffic forecasts to be important in negotiations for state funding and for justifying the need for capacity expansion. A municipal politician put it this way:

They [the forecasts] don't matter so much at the early stage. But they become important if you are to proceed with an idea... Then they are decisive for the acceptance of the arguments. (Former city council member and chair of the municipal transport committee, Denmark, in interview November 2010)

The high levels of forecasting inaccuracy and bias found in previous studies, combined with the different sources of errors pointed at by our respondents and interviews, gives rise to serious concerns about existing forecasting practice and in particular the socioeconomic assessments into which the forecasts are fed. Many of the challenges of modeling and decision-making, such as the use of models with "fixed matrixes" not taking into account the feedback mechanisms leading to induced traffic, cross geographic boundaries (see, e.g., MOTOS, 2007; Hatzopoulou and Miller 2009). The lesson for practice to be learned from the ontological explanations of forecasting errors is that it is futile to try to make exact forecasts of the future traffic volume on a proposed piece of infrastructure. Instead, we propose to separate the so-called strategic, tactical and operational levels of traffic forecasting into three distinct methodological approaches reflecting the different degrees of openness/closure of the systems at hand: Scenario analyses at the strategic level (where different trajectories for the general, "background" growth or decrease in traffic can be explored); theory-informed, mainly qualitative analyses supplemented with simple calculations at the tactical level (where the changes in traffic volumes caused by a proposed project are assessed); while more traditional micro-simulations should be applied only at a detailed operational level (Næss and Strand 2012, 2015). Moreover, when assessing the impacts of a proposed project, it is crucial that induced traffic is included in the calculations.

The possibilities of different kinds of strategic misrepresentation call for a radically more transparent forecasting process than what is typically the case today. The lack of transparency characterizing most model-based forecasting work contributes to a reification of quantitative model output, despite the usually high degree of uncertainty and possible bias. In particular, the process will have a "black box" nature if the assumptions of the traffic model are dealt with as the "business secret" of a consultancy firm. Replacing traditional modeling at the tactical level with the theory-informed analyses and simpler calculations proposed here will in itself contribute to more transparency. In addition, the built-in assumptions of the analysis (whether model-based or based on simpler methods) should be quality controlled by independent external experts covering subject fields wider than that of the forecasters themselves. 


\section{Acknowledgements}

Thanks to Teresa Næss, who managed the distribution of questionnaires and transcribed the interviews. The project was carried out with a grant from the Danish Strategic Research Council.

\section{References}

Andersen, J. A. 2013 The shaping of transport model based knowledge production: An embedded case study of Danish transport modeling practice in a contemporary and historical perspective. Ph.D. thesis, Aalborg, Denmark: Aalborg University.

Bain, R. 2009. Error and optimism bias in toll road forecasts. Transportation 36(5): 469-482.

Bhaskar, R. 2008. A Realist Theory of Science. London and New York: Routledge.

Bradburn, N. M., S. Sudman, and B. Wansink. 2004. Asking Questions: The Definitive Guide to Questionnaire Design-For Market Research, Political Polls, and Social and Health Questionnaires. San Francisco: Jossey-Bass.

Danermark B., M. Ekström, L. Jacobsen, and J. C. Karlsson. 2001. Explaining Society. Critical Realism in the Social Sciences. London and New York: Routledge.

Eliasson, J., and M. Fosgerau. 2013. Cost overruns and demand shortfalls-deception or selection? Transportation Research Part B 57: 105-113.

Flyvbjerg, B. 2007. Policy and planning for large-infrastructure projects: problems, causes, cures. Environment and Planning B: Planning and Design 34(4): 578-597.

Flyvbjerg, B., N. Bruzelius, and W. Rothengatter. 2003. Megaprojects and Risk. An Anatomy of Ambition. Cambridge: Cambridge University Press.

Flyvbjerg, B., and COWI. 2004. Procedures for Dealing with Optimism Bias in Transport Planning. Guidance Document. London: Department for Transport.

Flyvbjerg, B., M. S. Holm, and S. Buhl. 2002. Underestimating costs in public works projects: Error or lie? Journal of the American Planning Association 68(3): 279-295.

Flyvbjerg, B., M. S. Holm, and S. Buhl. 2005. How (in)accurate are demand forecasts in public works projects? The case of transportation. Journal of the American Planning Association 71(2): 131-146.

Fouracre, P. R., R. J. Allport, and J. M. Thomson. 1990. The Performance and Impact of Rail Mass Transit in Developing Countries. Wokingham, UK: UK Transport and Road Research Laboratory.

Hatzopoulou, M., and E. J. Miller. 2009. Transport policy evaluation in metropolitan areas: The role of modeling in decision-making. Transportation Research Part A 43: 323-338.

Jonsson, D., and J. Johansson. 2006. Indirect effects to include in strategic environmental assessments of transport infrastructure investments. Transport Reviews 26: 151-166.

Mackie, P., and J. Preston. 1998. Twenty-one sources of error and bias in transport project appraisal. Transport Policy 5(1): 1-7.

MOTOS. 2007. Transport Modeling: Toward Operational Standards in Europe. MOTOS project EU. Handbook. http://www.motosproject.eu/?po_id=handbook.

NAO. 1988. Department of Transport, Scottish Development Department and Welsh Office: Road Planning. London: National Audit Office.

Newman, P. W. G., and J. R. Kenworthy. 1989. Cities and Automobile Dependence. Aldershot, UK: Gower.

Nicolaisen, M. S. 2012. Forecasts: Fact or fiction? Uncertainty and inaccuracy in transport project evaluation. Ph.D. thesis. Aalborg, Denmark: Aalborg University.

NOU 1999:28. 1998. Gardermoprosjektet: Evaluering av Planlegging og Gjennomforing. (The Gardermoen 
Project: Evaluation of Planning and Implementation.) Report from a committee appointed through Royal Resolution of May 15, 1998. Oslo: National government.

Næss, P. 2011. The third Limfjord crossing. A case of pessimism bias and knowledge filtering. Transport Reviews 31(2): 231-249.

Næss, P., J. Andersen, M. S. Nicolaisen, and A. Strand. 2014. Transport modeling in the context of the predict and provide paradigm. Forthcoming in European Journal of Transport and Infrastructure Research 14(2).

Næss, P., B. Flyvbjerg, and S. Buhl. 2006. Do road planners produce more honest numbers than rail planners? An analysis of accuracy in road-traffic forecasts in cities versus peripheral regions. Transport Reviews 26(5): 537-555.

Næss, P., M. S. Nicolaisen, and A. Strand. 2012. Traffic forecasts ignoring induced demand: A shaky fundament for cost-benefit analyses. European Journal of Transport and Infrastructure Research 12(3): 291-309.

Næss, P., and A. Strand. 2012. What kinds of traffic forecasts are possible? Journal of Critical Realism 11(3): 277-295.

Næss, P., and A. Strand. 2015. Traffic forecasting at strategic, tactical and operational level: A differentiated methodology is necessary. DISP 51 (2): $41-48$.

Osland, O., and A. Strand. 2008. Evaluating large transport infrastructure projects— a critical-constructive review of the theory of strategic misrepresentation. Presented at the conference Infrastructure Systems and Services: Building Networks for a Brighter Future (INFRA), November 10-12, Rotterdam.

Parthasarathi, P., and D. Levinson. 2010. Post construction evaluation of traffic forecast accuracy. Transport Policy 12(6): 428-43.

Pickrell, D. H. 1990. Urban Rail Transit Projects: Forecast Versus Actual Ridership and Cost. Washington, DC: Urban Mass Transportation Administration.

Tennøy, A. 2003. Bidrar bruk av transportanalyser i byplanleggingen til vekst $i$ biltrafikken? Paper for the conference Traffic Days at Aalborg University, August 25-26, Aalborg, Denmark.

Wachs, M. 1989. When planners lie with numbers. Journal of the American Planning Association 55(4): 476-479.

Welde, M., and J. Odeck. 2011. Do planners get it tight? The accuracy of travel demand forecasting in Norway. European Journal of Transport and Infrastructure Research 11(1): 80-95. 


\section{Notes}

${ }^{1}$ The rates of missing answers differ somewhat between the explanatory categories, but this simply reflects variation across explanatory categories in the number of questions asking about the occurrence of circumstances without explicitly referring to these circumstances as sources of inaccuracy. The missing rates do not appear to depend on the order in which the questions associated with different explanations were posed. The explanatory categories of the 19 questions represented in Figures 1-4 appeared in the questionnaire in the following order: technical, strategic, strategic, technical, technical, technical, strategic, technical, technical, optimistic, ontological, ontological, ontological, strategic, ontological, ontological, ontological, ontological, combined optimistic/strategic.

${ }^{2}$ A third possible reason for leaving certain questions unanswered might be that the answers, if given, would display examples of socially disapproved professional conduct. The rate of missing answers for a question asking about deliberate manipulation as a potential cause of inaccuracy is, however, similar to those for the remaining questions about causes of forecasting inaccuracy, and for several other questions addressing dubious practices without explicitly referring to these practices as sources of forecasting errors, the rates of missing answers are zero.

${ }^{3}$ For each of the questions in Figures 1 and 2, the answer alternatives were introduced by a text asking the respondents to indicate for each statement how much they agreed with this statement being a main explanation for potential inaccuracy in traffic forecasts.

${ }^{4}$ Admittedly, the statement that more advanced models would yield more accurate results was rather vaguely formulated, and the threshold of agreeing was perhaps somewhat low since it was not stated how much more accurate the models ought to be. Comparing the answers to this question to the respondents' assessments of, respectively, average and acceptable levels of forecasting inaccuracies may, however, shed some light on this. Among the 63 percent of the respondents who fully or partly agreed that more advanced models would yield more accurate results, only 8 percent considered inaccuracy of 30 percent or more to be acceptable, while 25 percent believed the actual inaccuracy to be at least 30 percent. And while only 15 percent of the mentioned group of respondents believed that the actual level of inaccuracy was less than 10 percent, the proportion that considered that the inaccuracy level should be below 10 percent to be acceptable was 27 percent.

${ }^{5}$ For questions $\mathrm{a}, \mathrm{b}, \mathrm{c}$ and $\mathrm{d}$, the answer alternatives were introduced by a text asking the respondents to indicate how much they agreed with each statement. For question e, the answer alternatives were introduced by a text asking the respondents to indicate for each statement how much they agreed in this statement being a main explanation for potential inaccuracy in traffic forecasts.

${ }^{6}$ See, e.g., Newman and Kenworthy 1989; Tennøy 2003; Næss, 2011.

${ }^{7}$ For questions $\mathrm{b}, \mathrm{c}$ and $\mathrm{d}$, the answer alternatives were introduced by a text asking the respondents to indicate how much they agreed with each statement. For question a and e, the answer alternatives were introduced by a text asking the respondents to indicate for each statement how much they agreed with this statement being a main explanation for potential inaccuracy in traffic forecasts. 